\title{
Kinetic Aspects of Tetrahydrobenzo[b]pyran Formation in the Presence of Agar as a Green Catalyst: A Mechanistic Investigation
}

\author{
Mehdi Shahraki*, Sayyed Mostafa Habibi-Khorassani and \\ Sayyedeh Shadfar Pourpanah
}

Department of Chemistry, University of Sistan and Baluchestan, P.O.Box 98135-674, Zahedan, Iran.

http://dx.doi.org/10.13005/bbra/2090

(Received: 11 March 2016; accepted: 17 April 2016)

\begin{abstract}
The kinetic and mechanism of the reaction between benzaldehyde, malononitrile and dimedone has been studied in the presence agar as a highly efficient homogenous catalyst in a mixture of (water/ethanol, 2:1). Based on the experiment data, the overall order of reaction for the formation of tetrahydrobenzo[b]pyran followed second-order kinetics and under pseudo-order conditions the partial orders with respect to 1,2 and 3 were one, one and zero, respectively. From the temperature, concentration and solvent studies, the activation energy $\left(E_{\mathrm{a}}\right)$ and the related kinetic parameters $\left(\Delta G^{\ddagger}, \Delta S^{\ddagger}\right.$ and $\left.\Delta H^{\ddagger}\right)$ are calculated. The first step of the proposed mechanism is recognized as a rate-determining step $\left(k_{1}\right)$ and this is proved by the steady state approximation.
\end{abstract}

Key words: Kinetics, Mechanism, Tetrahydrobenzo[b]pyran, Agar, Catalyst.

Multicomponent reactions (MCRs) have emerged as an efficient and powerful tool in modern organic chemistry towards the generation of highly diverse and complex product from readily available substrates in a single operation without isolation of intermediates in minimal time with maximum selectivity, high atom-economy and high purity with excellent yields. MCRs have an outstanding status in medicinal chemistry and modern organic synthesis because they are one-pot processes that assemble three or more components ${ }^{1,2}$.

Tetrahydrobenzo[b]pyran and their derivatives possess potent biological activities like antitumor, antibacterial, antiviral, antitubercular and spasmolytic activities ${ }^{3-7}$.

Previously, tetrahydropyran was produced by the cycliza-tion of arylidenemalononitriles with b-dicarbonyl compounds in the presence of bases such as piperidine ${ }^{8}$, triethylamine ${ }^{9}$, magnesium oxide ${ }^{10}, \mathrm{Mg} /$ $\mathrm{La}^{11}$, PEG1000-DAIL/EM ${ }^{12}$, and nano $\mathrm{ZnO}^{13}$.

\footnotetext{
* To whom all correspondence should be addressed. Tel.:+98 541 2446565; Fax: +98 541 2446565;

E-mail: mehdishahraki@chem.usb.ac.ir
}

Consequently, diethyl 2,6-dimethyl-4-aryl-4Hpyran-3,5-dicarboxylates was synthesized with a low yield, utilizing $\mathrm{ZnCl}_{2}$ as a catalyst, acetic anhydride as the solvent, and column chromatography as the purification method ${ }^{14,15}$.

In recent years, the emphasis of science and technology has shifted more toward environmental benign and sustainable resources and progress: in this regard, has led to using of natural catalysts considerably; attention in organic chemistry. In particular, natural biopolymers are important candidates to explore for catalysts and their properties provided the possibility to perform reactions for acid-sensitive substrates, under milder reaction conditions and better selectivity ${ }^{16-}$ ${ }^{20}$.

Based on the previous studies on the use of heteropolyacids as catalysts, and in a continuation of our endeavors for the development of simple and highly expedient methods for the synthesis of polyfunctionalized heterocycles of biological importance ${ }^{21-31}$, we examined the possibility of using agar as a catalyst for the onepot synthesis of tetrahydrobenzo[b]pyran by condensing benzaldehyde 1 , malononitrile 2 and 
dimedonein 3 in $\mathrm{H}_{2} \mathrm{O}$ /EtOH (Fig. 1).

Kinetic analysis often used to be studied to see what happens to the molecular level during a chemical reaction. The purpose of any kinetic study is to form a quantitative relationship between the rate of a reaction and the concentration of reagents or catalysts ${ }^{32}$. Thus, the best solution to meet this aim is simply to follow the disappearance of the starting material or appearance of a product as a function of time. This can be done by measuring the rate of a reaction at various concentrations of reactants and catalysts in order to determine the kinetic order with respect to a particular reactant and to establish an overall function which represents the rate law of a behavior reaction with a known rate constant ${ }^{33-52}$. Kinetics studies suggest many practical techniques to accomplish these measurements. Numerous kinetics investigations over a large area of different reactions have previously been reported using the UV-vis technique ${ }^{53-60}$.

In this work, we describe kinetic results together with detailed mechanistic studies of the synthesis reaction of $4 \mathrm{H}$-tetrahydrobenzo[b]pyran based on a global kinetic analysis methodology using the UV-vis spectrophotometry apparatus.

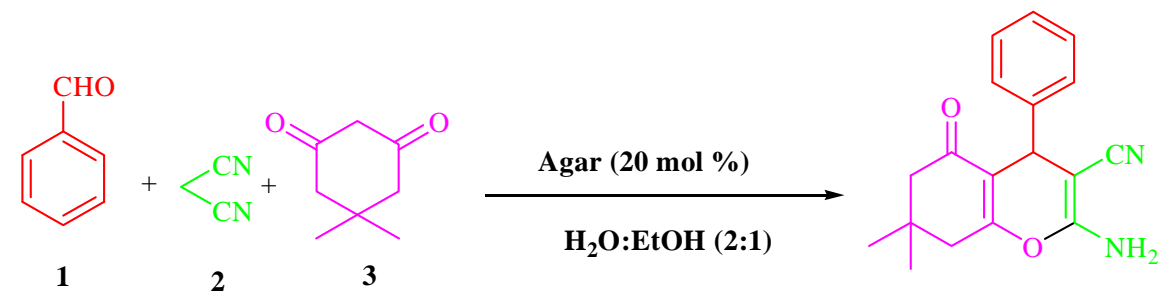

Fig. 1. Synthesis of tetrahydrobenzo[b]pyran in the presence of agar in a mixture of (water/ethanol, 2:1)

\section{EXPERIMENTAL}

\section{Chemicals and Apparatus used}

All reagents were obtained from Merk and Aldrich and used without any purification. Rate constants are presented as an average of several kinetic runs (at least 6-10) and are reproducible within $\pm 3 \%$. The overall rate of reaction is followed by monitoring absorbance changes of the products with time on a Varian (Model Cary Bio-300) UV-vis spectrophotometer with a $10 \mathrm{~mm}$ light-path cell. Temperature of the reaction is maintained to within $\pm 0.1^{\circ} \mathrm{C}$ at various temperatures by circulating a mixture of water and ethylenglaycol bath.

\section{RESULTSAND DISCUSSION}

\section{Kinetics}

The UV/vis technique was exploited as a useful tool to further study about the mechanism of the reaction between benzaldehyde $\mathbf{1}$, malononitrile $\mathbf{2}$ and dimedone $\mathbf{3}$ in the presence of agar in a mixture of (water/ethanol, 2:1). First, for the kinetic measurements, it was essential to obtain an appropriate wavelength in order to follow the reaction kinetics. To gain it, in the first experiment,
$10^{-2} \mathrm{M}$ solution of each reactant $\mathbf{1}, \mathbf{2}, \mathbf{3}$ and $2 \times 10^{-3}$ M solution of agar were prepared in a mixture of (water/ethanol, 2:1) as solvent. Approximately 3 $\mathrm{mL}$ aliquot from each reactant was pipetted into a $10 \mathrm{~mL}$ light path quartz spectrophotometer cell and the relevant spectrum of each compound at $25^{\circ} \mathrm{C}$ was recorded over the wavelength range 250-480 $\mathrm{nm}$. In the second experiment, $0.2 \mathrm{~mL}$ aliquot of $8 \times 10^{-3} \mathrm{M}$ solution of agar and $0.2 \mathrm{~mL}$ aliquot of $4 \times 10^{-2} \mathrm{M}$ solution of reactants 1 and 3 were pipetted into a quartz spectrophotometer cell, then $0.2 \mathrm{~mL}$ aliquot of $4 \times 10^{-2} \mathrm{M}$ solution of reactant 2 was added to the mixture according to stoichiometry of each reactant in the overall reaction. The reaction was monitored by recording scans of the entire spectra with 20 minute intervals during the whole reaction time at the ambient temperature (Fig. 2). As can be seen in Fig. 2, the appropriate wavelength was discovered to be $380 \mathrm{~nm}$ (corresponding mainly to the product 3 ). Since at this wavelength, reactants 1, 2, 3 and agar have relatively no absorbance value, it gave us the chance to find the practical conditions that allows kinetics and a mechanistic investigation of the reaction. Herein, in all the experiments, the UV-vis spectrum of the product was measured over the concentration range $\left(10^{-}\right.$ 
${ }^{4} \mathrm{M} \leq \mathrm{M}$ product $\leq 10^{-2} \mathrm{M}$ ) to confirm a linear relationship between the absorbance and concentrations values.

In the third experiment, under the same concentration $\left(10^{-2} \mathrm{M}\right)$ of 1,2 and 3 in the presence of agar $\left(2 \times 10^{-3} \mathrm{M}\right)$ in a mixture of (water/ethanol $2: 1)$ at $35^{\circ} \mathrm{C}$, the reaction kinetics was followed by indicating the UV absorbance measurements versus time (Fig. 3.).

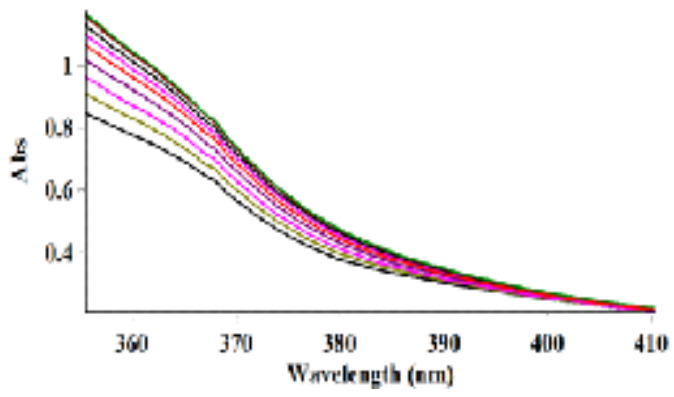

Fig. 2. The UV-vis spectra of the reaction between benzaldehyde $\mathbf{1}\left(10^{-2} \mathrm{M}\right)$, malononitrile $2\left(10^{-2} \mathrm{M}\right)$ and dimedone $3\left(10^{-2} \mathrm{M}\right)$ in the presence of agar $\left(2 \times 10^{-3}\right.$ $\mathrm{M})$ as a catalyst in a mixture of (water/ethanol, 2:1) as reaction proceeds into a $10 \mathrm{~mm}$ light-path cell. Herein, the upward of direction of the arrow indicate that the progress of product versus times

The infinity absorbance $\left(\mathrm{A}_{\infty}\right)$ was obtained at 30 minutes as reported in Fig. 3. With respect to this value, zero, first or second curve fitting could be drawn automatically for the reaction by the software associated [61] with the UV instrument. A second order fit curve (solid line) was obtained from the absorbance data versus time provided at $380 \mathrm{~nm}$ that precisely described the experimental curve (dotted line) as reported in Fig. 3. It is obvious that the reaction is second order. Thus, overall order of reaction is $\alpha+\beta+\gamma=$ 2.therfore the second-order rate constant can be reported $\left(\mathrm{k}_{\text {over }}=5.47 \mathrm{~min}^{-1} \cdot \mathrm{M}^{-1}\right)$.

In this case, rate law can be written as:

$$
\text { rate }=k_{\text {ovr }}[1]^{\alpha}[2]^{\beta}[3]^{\gamma}[\text { Cat }]
$$

\section{Effect of Solvents and Temperature}

To assess the effect of changes in temperature and the solvent environment on the rate of reaction, it was decided to perform various experiments under different temperatures and solvent polarities, but, under the same condition as the earlier experiments.

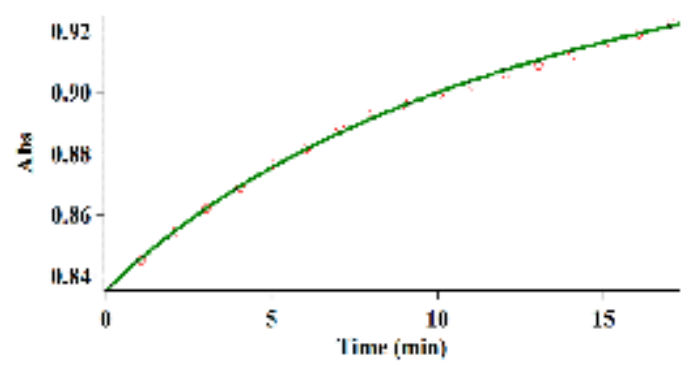

Fig. 3. The experimental absorbance change (dotted line) along with the fit curve (solid line) against time for the reaction between benzaldehyde $1\left(10^{-}\right.$ ${ }^{2} \mathrm{M}$ ), malononitrile $2\left(10^{-2} \mathrm{M}\right)$, and dimedone $3\left(10^{-}\right.$ $\left.{ }^{2} \mathrm{M}\right)$ in the presence of agar $\left(2 \times 10^{-3} \mathrm{M}\right)$ in a mixture of (water/ethanol, 2:1) at $380 \mathrm{~nm}$ and $35.0^{\circ} \mathrm{C}$.

Because the transition state (Step 1, Fig. 9) in reaction carries a dispersed charge, solvents with higher dielectric constant speed up reaction rate (Table 1) by stabilizing the species at the transition state more than reactants, and therefore $\mathbf{E}_{\mathbf{a}}$ would be lower.

In the temperature range used in this investigation, the relation of the second order rate constant $\left(\ln _{1}\right)$ of the reactions on reciprocal temperature confirms Arrhenius equation. This manner is indicated in (Fig. 4). The activation energy, for the reaction between $\mathbf{1}, \mathbf{2}$ and $\mathbf{3}$ was acquired $\left(107.13 \pm 1.38 \mathrm{~kJ} . m o l^{-1}\right)$ forming the slope of (Fig. 4).

Based on Eyring equations (2) and (3) the activation parameters $\Delta \mathrm{H}^{\ddagger}$ (activation enthalpy) and $S^{\ddagger}$ (activation entropy) were determined using the intercept and slope, respectively (Fig. 5).

$$
\begin{aligned}
& \ln \left(\frac{\mathrm{k}}{\mathrm{T}}\right)=\left(\ln \frac{\mathrm{k}_{\mathrm{B}}}{\mathrm{h}}+\frac{\Delta S^{\ddagger}}{\mathrm{R}}\right)-\frac{\Delta H^{\ddagger}}{\mathrm{RT}} \\
& \mathrm{T} \times \ln \left(\frac{\mathrm{k}}{\mathrm{T}}\right)=\mathrm{T} \times\left(\ln \frac{\mathrm{k}_{\mathrm{B}}}{\mathrm{h}}+\frac{\Delta S^{\ddagger}}{\mathrm{R}}\right)-\frac{\Delta H^{\ddagger}}{\mathrm{R}}
\end{aligned}
$$

That $\mathbf{k}_{\mathbf{B}}$ is Boltzmann's constant, $\mathbf{T}$ is temperature, $\mathbf{h}$ is Planck's constant and $\mathbf{R}$ is universal gas constant.

Herein, the Eyring equation suggests that the standard errors of $\Delta \mathbf{S}^{\ddagger}$ and $\Delta \mathbf{H}^{\ddagger}$ are related to each other through equation (4).

$$
\sigma\left(\Delta S^{\ddagger}\right)=1 / T_{\mathrm{av}} \sigma\left(\Delta H^{\ddagger}\right)
$$

In this equation $\mathbf{T}_{\mathrm{av}}$ is known to be the center of the temperature range that is used in this 
Table 1. $k_{\text {obs }}\left(\mathrm{M}^{-2} \mathrm{~min}^{-1}\right)$ for the reaction between $1\left(10^{-2} \mathrm{M}\right), 2\left(10^{-2} \mathrm{M}\right)$ and $3\left(10^{-2} \mathrm{M}\right)$ and agar $\left(2 \times 10^{-3} \mathrm{M}\right)$ in different solvent media and temperatures

\begin{tabular}{|c|c|c|c|c|}
\hline \multicolumn{5}{|c|}{ Solvent: mix of water/ethanol (2:1) (60.9) ${ }^{\mathrm{a}}$} \\
\hline $\mathrm{T}$ & $\mathrm{T}=298.15 \mathrm{~K}$ & $\mathrm{~T}=303.15 \mathrm{~K}$ & $\mathrm{~T}=308.15 \mathrm{~K}$ & $\mathrm{~T}=313.15 \mathrm{~K}$ \\
\hline$k_{\text {obs }}$ & $\begin{array}{c}1.23 \\
(0.0027)^{\mathrm{b}}\end{array}$ & $\begin{array}{c}2.65 \\
(0.0022)\end{array}$ & $\begin{array}{c}5.47 \\
(0.0015)\end{array}$ & $\begin{array}{c}9.62 \\
(0.0010)\end{array}$ \\
\hline \multicolumn{5}{|c|}{ Solvent: ethanol $(24.3)^{\mathrm{a}}$} \\
\hline $\mathrm{T}$ & $\mathrm{T}=298.15 \mathrm{~K}$ & $\mathrm{~T}=303.15 \mathrm{~K}$ & $\mathrm{~T}=308.15 \mathrm{~K}$ & $\mathrm{~T}=313.15 \mathrm{~K}$ \\
\hline$k_{\mathrm{obs}}$ & $\begin{array}{c}0.43 \\
(0.0016)^{\mathrm{b}}\end{array}$ & $\begin{array}{c}1.03 \\
(0.0013)\end{array}$ & $\begin{array}{c}2.83 \\
(0.0018)\end{array}$ & $\begin{array}{c}5.96 \\
(0.0020)\end{array}$ \\
\hline
\end{tabular}

investigation. It follows that in most solution phase studies $\sigma\left(\Delta \mathrm{S}^{\ddagger}\right) \approx\left(\Delta \mathrm{H}^{\ddagger}\right) \times 0.003 \mathrm{~K}^{-1}$. This correlation has been mentioned elsewhere [62-64]. The standard errors for activation parameters have been calculated and they have been reported along with these parameters in both Table 2.

Furthermore, $\Delta \mathrm{G}^{\ddagger}$ (Gibbs free energy) was determined using the equation (5):

$$
\Delta G^{\ddagger}=\Delta H^{\ddagger}+T \Delta S^{\ddagger}
$$

According to equation (22), $k_{1}$ is proportional to the general reaction rate, hence, the activation parameters which include, $\Delta S^{\ddagger}$ and $\ddot{A} H^{\ddagger}$ can now be computed for the first step (rate determining step, $k_{1}$ ), as an elementary reaction. Obtained activation parameters for two solvents are given in Table 2.

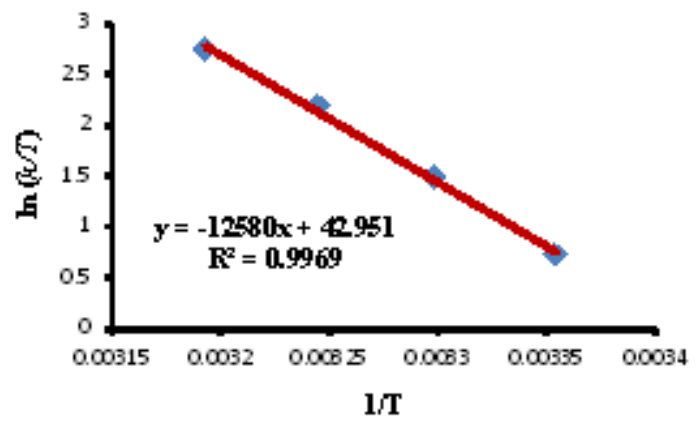

Fig. 5. Eyring plots according to equation (2) for the reaction between $\mathbf{1}, \mathbf{2}$ and $\mathbf{3}$ in the presence of agar in a mixture of (water/ethanol, 2:1)

b: standard deviation (SD).

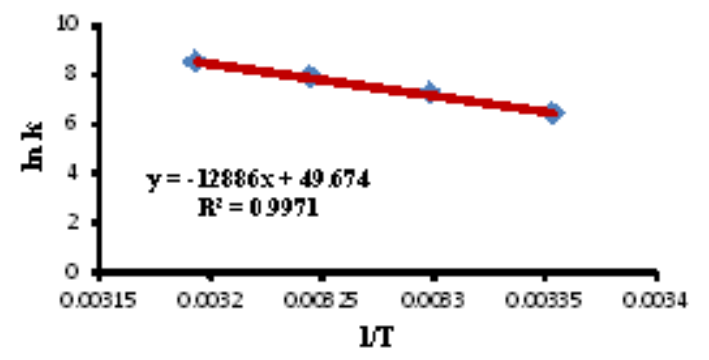

Fig. 4. The dependence of the second order rate constant (lnk) on reciprocal temperature for the reaction between 1, $\mathbf{2}$ and $\mathbf{3}$ in the presence of agar measured at a wavelength of $380 \mathrm{~nm}$ in a mixture of (water/ethanol, 2:1) according to the Arrhenius equation

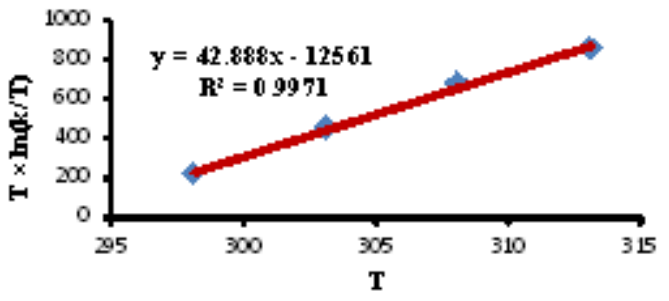

Fig. 6. Eyring plots in accordance with equation (3) for the reaction between $\mathbf{1 ,} \mathbf{2}$ and $\mathbf{3}$ in the presence of agar in a mixture of (water/ethanol, 2:1)

Table 2. Activation parameters for the reaction between compounds 1, 2, 3 and agar measured in different solvent media

\begin{tabular}{|c|c|c|c|c|}
\hline solvent & $\Delta H^{\ddagger}\left(\mathrm{kJ} \mathrm{mol}^{-1}\right)$ & $\Delta S^{\ddagger}\left(\mathrm{Jmol}^{-1}\right)$ & $\Delta G^{\ddagger}\left(\mathrm{kJ} \mathrm{mol}^{-1}\right)$ & Ea (kJ D mol) \\
\hline water/ethanol (2:1) (58.6) ${ }^{\mathrm{a}}$ & $104.43 \pm 1.39$ & $159.03 \pm 4.55$ & $57.01 \pm 2.75$ & $106.91 \pm 1.39^{b} \quad 107.13 \pm 1.38^{c}$ \\
\hline ethanol $(24.3)^{\mathrm{a}}$ & $135.64 \pm 1.62$ & $254.65 \pm 5.30$ & $56.77 \pm 0.79$ & $138.04 \pm 1.62^{\mathrm{b}} \quad 138.17 \pm 1.62$ \\
\hline
\end{tabular}

a: dielectric constant (D) b: according to this equation: Ea $=\mathrm{DH}^{\hat{A}}+\mathrm{RT}$

c: in accord with the Arrhenius equation 
The significant value of $\mathbf{E}_{\text {a }}$ shows that the reactant needs much energy for reaching transition state. The value of activation enthalpy $\left(\Delta \mathrm{H}^{\ddagger}\right)$ and free energy of activation $\left(\Delta \mathrm{G}^{\ddagger}\right)$ are positive and have rather large values which suggest that the energy required for the reaction is relatively high. A positive value for entropy of activation $\left(\Delta S^{\ddagger}\right)$ indicates that the transition state is highly disordered compared to the ground state. Looking at detail, the activation enthalpy is lower in solvent with high dielectric constant (water/ethanol, 2:1) with respect to lower dielectric constant (ethanol) at same temperature, and this give rise to lower activation energy for reaction in solvent with high dielectric constant because $\mathrm{E}_{\mathrm{a}}$ is directly proportional to the activation enthalpy $\left(\mathrm{E}_{\mathrm{a}}=\mathrm{DH}^{\ddagger}+\right.$ RT). Therewith, the positive value of $\Delta \mathrm{G}^{\ddagger}$ is a sign for the reaction to be spontaneous.

\section{Effect of concentration}

In this experiment to estimate partial order of reactant $\mathbf{3}$ under pseudo-order condition, in the separate experiment (fourth experiment), same procedure was employed with these concentrations $\left[\left(10^{-2} \mathrm{M}\right.\right.$, reactant $\left.\mathbf{1}\right),\left(10^{-2} \mathrm{M}\right.$, reactant 2$)],\left[\left(5 \times 10^{-3} \mathrm{M}\right.\right.$, reactant 3$\left.)\right]$ and agar $\left(2 \times 10^{-}\right.$ ${ }^{3} \mathrm{M}$ ). For obtaining equation (6), the rate law can be expressed:

$$
\begin{gathered}
\text { rate }=k_{\text {ovr }}[1]^{\alpha}[2]^{\beta}[3]^{\gamma}[\text { Cat }] \\
\text { rate }=k_{\text {obs }}[3]^{\gamma}
\end{gathered}
$$

$k_{o b s}=k_{o v r}[1]^{\alpha}[2]^{\beta}[$ Cat $]$

Herein, the original experimental absorbance versus time data reported a secondorder behavior as a function of time. This is demonstrated as full line at $380 \mathrm{~nm}$ that truly fits the experimental result (Fig. 7). Additionally, the observed rate constant $\left(k_{\mathrm{obs}}\right)$ was automatically calculated by the software associated with UV/vis instrument $\left(\mathrm{k}_{\mathrm{obs}}=5.58\right)$

The experimental data displayed that the observed pseudo-second order rate constant $\left(k_{\mathrm{obs}}\right.$ $=5.58$, fourth experiment, pseudo-order condition) is identical with second order rate constant, $\left(\mathrm{k}_{\mathrm{obs}}=\right.$ 5.47 , secend experiment) which implies that probably $\gamma=0$ in equation (6).

In the fifth experiment, to assess a partial order of reaction in relevant to benzaldehyde $\mathbf{1}$, pseudo-order condition was defined for the

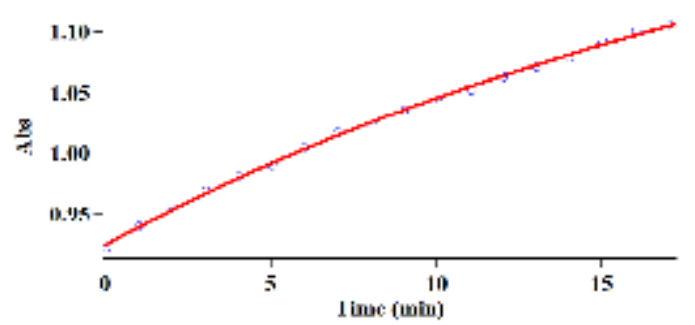

Fig.7. Pseudo-second order fit curve (solid line) along with the original experimental curved (dotted) for the reaction between dimedone $3\left(5 \times 10^{-3} \mathrm{M}\right)$,

malononitrile $2\left(10^{-2} \mathrm{M}\right)$ and benzaldehyde $\mathbf{1}\left(10^{-2} \mathrm{M}\right)$

in the presence of agar $\left(2 \times 10^{-3} \mathrm{M}\right)$ at $380 \mathrm{~nm}$ and $35.0^{\circ} \mathrm{C}$ in a mixture of (water/ethanol, 2:1)

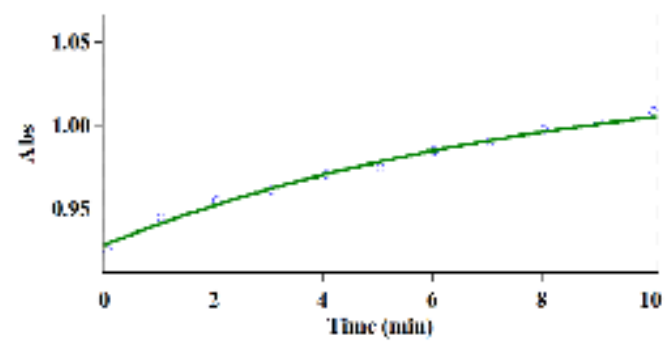

Fig. 8. Pseudo-First order fit curve (solid line) accompanied by the original experimental curve (dotted line) for the reaction between $\mathbf{1}\left(5 \times 10^{-3}\right.$ $\mathrm{M}), 2\left(10^{-2} \mathrm{M}\right)$ and $3\left(10^{-2} \mathrm{M}\right)$ in the presence of $\operatorname{agar}\left(2 \times 10^{-3} \mathrm{M}\right)$ at $380 \mathrm{~nm}$ and $35.0^{\circ} \mathrm{C}$ in

reaction between the $2\left(10^{-2} \mathrm{M}\right), \mathbf{3}\left(10^{-2} \mathrm{M}\right)$ and $\mathbf{1}$ $\left(5 \times 10^{-3} \mathrm{M}\right)$ in the presence of agar $\left(2 \times 10^{-3} \mathrm{M}\right)$ in a mixture of (water/ethanol, 2:1). According to the fifth experiment, the rate law can be expressed as:

$$
\begin{gathered}
\text { rate }=k_{\text {ovr }}[1]^{\alpha}[2]^{\beta}[3]^{\gamma}[\text { Cat }] \\
\text { rate }=k_{\text {obs }}[1]^{\alpha} \\
\text { rate }=k_{\text {ovr }}[2]^{\beta}[3]^{\gamma}[\text { Cat }]
\end{gathered}
$$

The original experimental absorbance versus time (full line) at $380 \mathrm{~nm}$ truly fits the experimental curve (dotted line), shown in Fig. 8.

$A+\beta+\gamma=2$ from third experiment, $\gamma=0$ on the basis of fourth experiment and $\alpha=1$ on the basis of fifth experiment. As $\alpha$ results $\beta$ is equal to one $(\beta=1)$.

So the rate low can be expressed:

rate $=k_{\text {ovr }}[1][2]$ [cat $]$

To investigate which steps of the proposed mechanism is a rate-determining step, 
<smiles>[CH]OC</smiles>

step1:

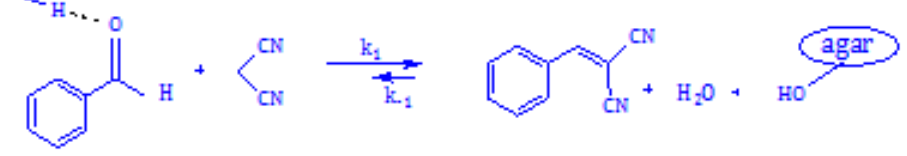

1

2

$I_{1}$

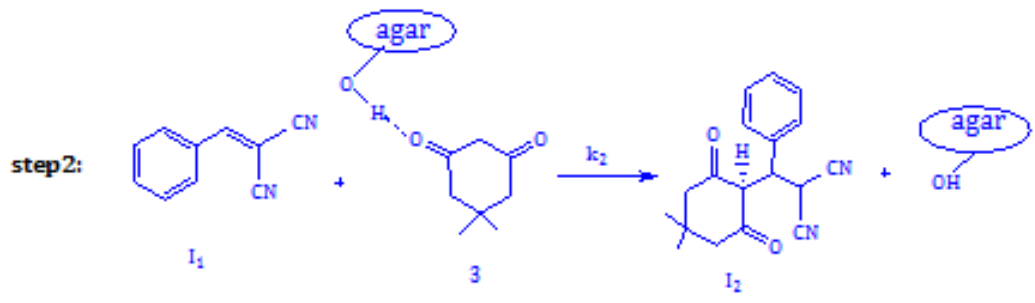<smiles>CC(C)C(C#N)C(c1ccccc1)C1C(=O)CC(C(C)(C)C)CC1=O</smiles>

$\mathrm{I}_{2}$

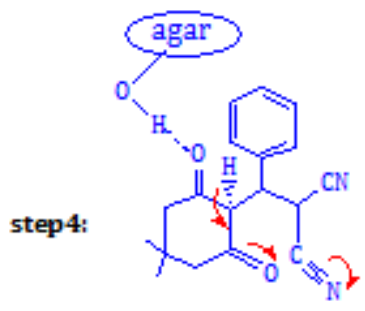

$\mathrm{I}_{2}$<smiles>CC1(C)CC(=O)C(C(c2ccccc2)C([Al])C[OH2+])=C(O)C1</smiles>

$\mathrm{I}_{3}$<smiles>[H][R]1([H])C2CC[C@@H]1C[C@H]2C</smiles>

$\mathrm{I}_{3}$

step5:<smiles>CC1CC2=C(OC1=N)C(C)CC(C)C(C)C2c1ccccc1</smiles><smiles>CC1(C)CC(=O)C2=C(C1)OC(N)=C(C#N)C2c1ccccc1</smiles>

4 (product)

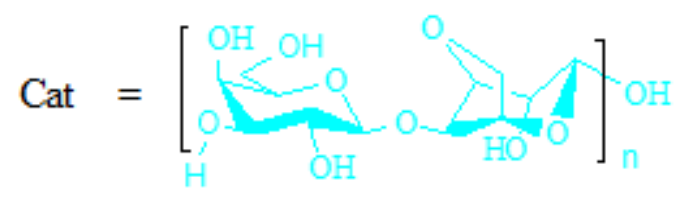

Fig. 9. A proposed mechanism of the reaction between $\mathbf{1}, \mathbf{2}$ and $\mathbf{3}$ in the presence of agar for synthesis of 2-amino-5,6,7,8-tetrahydro-7,7-dimthyl-4-(4-phenyl)5-oxo-4H-chromene-3-carbonitrile 4 in a mixture of (water/ethanol, 2:1 ). 
the rate law was written using the final step of reaction:

$$
\text { rate }=k_{5}\left[I_{4}\right]
$$

The steady-state approximation can be employed for $\left[\mathrm{I}_{1}\right]$ that yields the equation (10) in the following:

$$
\begin{aligned}
& \frac{d\left[I_{4}\right]}{d t}=k_{4}\left[I_{3}\right][\text { Cat }]-k_{5}\left[I_{4}\right]=0 \\
& k_{4}\left[I_{3}\right][\text { Cat }]=k_{5}\left[I_{4}\right]
\end{aligned}
$$

The value of $\left[\mathrm{I}_{4}\right]$ can be replaced in equation (9) to attain this equation:

$$
\text { rate }=k_{4}\left[I_{3}\right][\text { Cat }]
$$

For attaining the intermediate concentration $\left[\mathrm{I}_{3}\right]$ the following equation is yielded by applying the steady state approximation:

$$
\begin{aligned}
& \frac{d\left[I_{3}\right]}{d t}=k_{3}\left[I_{2}\right][\mathrm{Cat}]-k_{4}\left[I_{3}\right][\mathrm{Cat}]=0 \\
& k_{3}\left[I_{2}\right][\mathrm{Cat}]=k_{4}\left[I_{3}\right][\mathrm{Cat}]
\end{aligned}
$$

By substituting equation (13) in (12), the following equation is emerged:

$$
\text { rate }=k_{3}\left[I_{2}\right][\text { Cat }]
$$

The steady state approximation can then be applied for attaining the concentration of $\left[\mathrm{I}_{2}\right]$ which is represented in the following formula:

$$
\begin{gathered}
\frac{d\left[I_{2}\right]}{d t}=k_{2}\left[I_{1}\right][\text { Cat }][1]-k_{3}\left[I_{2}\right][\text { Cat }]=0 \\
k_{2}\left[I_{1}\right][\text { Cat }][1]=k_{3}\left[I_{2}\right][\text { Cat }] \\
\text { rate }=k_{2}\left[I_{1}\right][\text { Cat }][1] \\
\frac{d\left[I_{1}\right]}{d t}=k_{1}[1][2][\text { Cat }]-k_{-1}\left[I_{1}\right][\text { Cat }]-k_{2}[3]\left[I_{1}\right][\text { Cat }]=0 \ldots \\
{\left[I_{1}\right]=\frac{k_{1}[1][2]}{k_{-1}+k_{2}[3]}} \\
\text { rate }=\frac{k_{2}[3][\text { Cat }] \times k_{1}[1][2]}{k_{-1}+k_{2}[3]}
\end{gathered}
$$$$
\mathrm{k}_{4}, \mathrm{k}_{5} \text { and } \mathrm{k}_{3} \text { are not attained in equation }
$$

(20), therefore this rate constants have no chance to be a rate determining step, but step $1\left(\mathrm{k}_{1}\right)$ and step2 $\left(k_{2}\right)$ have a good opportunity to be a rate determining step.

If $\mathrm{k}_{2}$ is rate determining step, so the following speculation is reasonable: $\mathrm{k}_{2}[3]<<\mathrm{k}_{-1}$
The new equation can be presented:

$$
\text { rate }=\frac{k_{1} k_{2}[1][2][3][\text { cat }]}{k_{-1}}
$$

This equation is not compatible with the experimental rate law (equation4), because the presented equation (21) is a third-order reaction with respect to compounds 1,2 and 3 , while the obtained results from the UV experiments indicate that overall order of reaction is two.

If $\mathrm{k}_{1}$ is a rate determining step, the following assumption is logical: $\mathrm{k}_{2}[3]>>\mathrm{k}_{-1}$

So the new generation of the rate law can be expressed:

$$
\begin{aligned}
& \text { rate }=k_{1}[1][2][\text { Cta }] \\
& \left.\mathrm{K}_{1}=\mathrm{k}_{\text {ovr }}, \quad \mathrm{k}_{\text {obs }}=\mathrm{k}_{1} \text { [Cat }\right]
\end{aligned}
$$

The last equation (22) is the same as the rate law that obtained from the UV experiment (equation 4). It is obvious that the original order of the reaction is two. In addition, the order of the reaction with respect to each reactant (1, 2 and $\mathbf{3})$ is 1,1 and zero, respectively. Also, because of the presence of $k_{1}$ in the rate law (22), it becomes clear that the first step $\left(k_{1}\right)$ is a rate determining step.

On the basis of obtained results a speculative mechanism containing five steps to be proposed in accord with knoevenagal condensation between benzaldehyde $\mathbf{1}$, malononitrile 2, for generation of 2benzylidenemalononitrile $\mathbf{I}_{\mathbf{1}}$, Michael addition of $\mathbf{I}_{\mathbf{1}}$ with dimedone 3 producted $\mathbf{I}_{2}$ wich subsequently followed tautomerization and cyclization afforded the corresponding product 4 (Fig. 9).

A simplified scheme of the proposed reaction mechanism (Fig.9) is shown in Fig. 10.

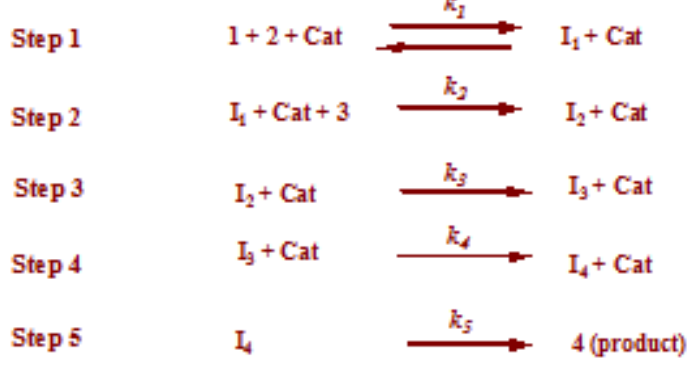

Fig. 10. A simplified Scheme for the proposed reaction mechanism 


\section{CONCLUSION}

In this article, we describe kinetic investigation of the reaction was done using UV spectrophotometry and the results are declared in the following terms. The overall order of reaction for the formation of a $4 \mathrm{H}$-tetrahydrobenzo[b]pyran in the presence of agar followed second-order kinetics and the partial orders with respect to benzaldehyde 1, malononitrile 2 and dimedone 3 were one, one and zero, respectively. The results indicated that the rate of reaction speeds up in solvent with high dielectric constant (water/ ethanol, 2:1 ) with respect to lower dielectric constant (ethanol) at all temperatures. In the studied temperature range, the second-order rate constant of the reaction was inversely proportional to the temperature, which agreed the Arrhenius equation. It's obvious that the difficult progress of the reaction is owing to the large positive value of activation parameters. From the temperature concentration and solvent studies, the activation energy $\left(E_{\mathrm{a}}\right)$ and the related kinetic parameters ( $\mathrm{A} G^{\ddagger}$, $\ddot{A} S^{\ddagger}$ and $\left.\ddot{A} H^{\ddagger}\right)$ are calculated. It's obvious that the large positive value of activation parameters leads to a stiff reaction progress. The first step of proposed mechanism was recognized as a ratedetermining step $\left(k_{1}\right)$ and this was confirmed based on the steady-state approximation.

\section{ACKNOWLEDGEMENTS}

We would like to extend our gratitude of Sistan and Baluchestan University for providing the financial protection of this work.

\section{REFERENCES}

1. J. Zhu, H. Bienayme, Multicomponent reactions, Wiley-VCH, Weinheim, 2005.

2. J. Safari, Z. Zarnegar, M. Heydarian, Journal of Taibah University for Science. 7, 17 (2013).

3. J. L. Wang, D. Liu, Z. J. Zhang, S. Shan, X. Han, S. M. Srinivasula, C. M. Croce, E. S. Alnemri, Z. Huang, Proc. Natl. Acad. Sci. 97, 7124 (2000).

4. N. R. Kamdar, D. D. Haveliwala, P. T. Mistry, S. K. Patel, Design, Eur. J. Med. Chem. 45, 5056 (2010).

5. A. G. Martinez, L. J. Marco, Bioorg. Med. Chem. Lett. 7, 3165 (1997).

6. H. Valizadeha, A. A. Azimi, J. Iran. Chem. Soc.
8, 123 (2011).

7. D. Arnesto, W. M. Horspool, N. Martin, A. Ramos, C. Seaone, J. Org. Chem. 54, 3069 (1989).

8. N. Martin, C. Pascual, C. Seoane, J. L. Soto, Heterocycles. 26, 2811 (1987).

9. S. E. Zayed, E. I. AbouElmaged, S. A. Metwally, M. H. Elnagdi. Czech. Chem. Commun. 56, 2175 (1991).

10. D. Kumar, R.V. Buchi, S. Sharad, U. Dube, S. Kapur, Eur. J. Med. Chem. 44, 3805 (2009).

11. N. SeshuBabu, N. Pasha, K. T. VenkateswaraRao, P. S. Sai Prasad, N. Lingaiah, Tetrahedron Lett. 49 2730(2008).

12. D. Fang, J. M. Yang, H. B. Zhang, C. M. Jiao, J. Ind. Eng. Chem. 17, 386 (2011).

13. P. Bhattacharyya, K. Pradhan, S. Paul, A. R. Das, Tetra-hedron Lett. 53, 4687 (2012).

14. J. Wolinsky, H. S. Haue, Substituted g-pyrans, J. Org. Chem. 34, 3169 (1969).

15. J. C. Wilson, G. S. Mcgrath, S. A. Srinivasan, US Patent, 6, 550 (2001).

16. P. K. Sahu, S. K. Gupta, D. D. Agarwal, Ind. Eng. Chem. Res, 53, 2085 (2014).

17. S. Shinde, G. Rashinkar, R. Salunkhe, Journal of Molecular Liquids, 178, 122 (2013).

18. N. Hazeri, M. T. Maghsoodlou, F. Mir, M. Kangani, H. Saravani, E. Molashahi, Chin. J. of Catal, 35, 1 (2014).

19. P. P. Salvi, A. M. Mandhare, A. S. Sartape, D. K. Pawar, S. H. Han, S. S. Kolekar, C. R. Chimie 14, 878 (2011).

20. P. A. Grieco, (Ed.), Blackie, London, 1998.

21. M. T. Maghsoodlou, S. M. Habibi-Khorassani, A. Moradi, N. Hazeri, A. Davodi, S. S. Sajadikhah, Tetrahedron, 67, 8492 (2011).

22. M. T. Maghsoodlou, S. M. Habibi-Khorasani, R. Heydari, N. Hazeri, S. S. Sajadikhah, M. Rostamizadeh, L. Keishams. Turk. J. Chem. 34, 565. (2010).

23. M. R. Mousavi, N. Hazeri, M. T. Maghsoodlou, S. Salahi, S. M. Habibi-Khorassani, Chin. Chem. Lett. 24, 411 (2013).

24. F. Noorisadeh, M. T Maghsoodlou, N. Hazeri, M. Kangani. Res. Chem. Intermed (2014) doi: 10.1007/s11164-014-1710-x.

25. L. M. Wang, J. H. Shao, H. Tian, Y. H.Wang, B. Liu, J Fluorine Chem. 127,97 (2006).

26. J. M. Khurana, S. Kumar, Tetrahedron Lett. 50, 4125 (2009).

27. D. Jpsita, J. B. Pulak. Tetrahedron Lett. 45, 8625 (2004).

28. T. S. Jin, A. Q. Wang, X. Wang, J. S. Zhang, T. S. Li, Synlett. 871 (2004).

29. N. M. A. El-Rahaman, A. A. El-Kateb, M. F. 
Mady. Synth Commun. 37, 3961 (2007).

30. S. Gurumurthi, V. Sundari, R. Valliappan. Eur. J. Chem. 6, 466 (2009).

31. S. T. Tu, Y. Gao, C. Guo, D. Q. Shi, Z. S. Lu. Synth. Commun. 32, 2137 (2002).

32. F. A. Carey, R. J. Sundberg. Kluwer Academic Press, New York, 2000.

33. G. V. M. Sharma, K. L. Reddy, P. S. Lakshmi, P. R. Krishna. Synthesis, 01, 55(2006).

34. O. J. Nielsen, J. Sehested, S. Langer, E. Ljungstrom, I. Wangberg. Chem Phys Lett, 238, 359(1995).

35. S. Langer, E. Ljungstrom, T. Ellermann, O. J. Nielsen, J. Sehested. Chem Phys Lett, 240, 53(1995).

36. V. V. Ivanov, C. Decker. Polym Int, 50, 113(2001).

37. P. C. Fung, K. M. Sin, S. M. Tsui. Color Technol, 116, 170(2000).

38. F. Misiti, M. Castagnola, C. Zuppi, B. Giardina, I. Messana. Biochem J, 356,799(2001).

39. K. Brudnik, M. Twarda, D. Sarzyn 'ski, J. T. Jodkowski. J Mol Model, 19, 1489(2013).

40. M. C. Almandoz, Y. A. Da 'vila, M. I. Sancho, E. I. Gasull, S. E. Blanco. Spectrochim Acta Part A, 77, 51(2010)

41. L. L. Lu, Y. H. Li, X. Y. Lu. Spectrochim Acta Part A, 74,829(2009).

42. V. V. Tatarchuk, A. P. Sergievskaya, I. A. Druzhinina, V. I. X. Zaikovsky. J Nanopart Res, 13, 4997(2011).

43. D. Reddy, K. J. Akerman, M. P. Akerman, D. Jaganyi. Transit Met Chem, 36, 593(2011).

44. Z. D. Bugarcic, J. Rosic, B. Petrovic, N. Summa, R. Puchta, R.V Eldik. J Biol Inorg Chem, 12, 1141(2007).

45. M. D. Rvovic, V. M. Divac, R. Puchta, Z. M. Bugarc ic. J Mol Model, 17, 1251(2011).

46. J. J. C. Erasmus, M. M. Conradie, J. Conradie. React Kinet Mech Cat, 105, 233(2012).

47. A. Rilak, B. Petrovic, S. Grguric Sipka, Z. Tesic, Z. D. Bugarc ic. Polyhedron, 30, 2339(2011).

48. B. P. Kalyan, K. S. Gupta. Transit Met Chem, 37, 671(2012).
49. A. K. Chandra. J Mol Model, 18, 4239(2012).

50. L. Sandhiya, P. Kolandaivel, K. Senthilkumar. Struct Chem, 23, 1475(2012).

51. M. Pandeeswaran, K. P. Elango. J Solut Chem, 38, 1558(2009).

52. O. Altun, H. Akbas. J Chem Thermodyn, 39, 1413(2007).

53. M. A. Kazemian, P. Karimi, S. M. HabibiKhorassani, A. Ebrahimi, F. Jalili-Milani. Prog React Kinet Mech. 34, 7(2009).

54. M. A. Kazemian, S. M. Habibi-Khorassani, M. T. Maghsoodlu, A. Ebrahimi. J Mol Model, 20, 2103(2014).

55. S. M. Habibi-Khorassani, M. T. Maghsoodlou, M. Shahraki, S. Talaie Far, M. R. Mousavi. Adv in Phys Chem. 1, 2014(2014)

56. S. M. Habibi-Khorassani, M. T. Maghsoodlou, A. Ebrahimi, H. Saravani, M. Zakarianejad, M. Ghahramaninezhat, M. A. Kazemian, M. Nassiri, Z. Khajali. Prog React Kinet Mech, 34,301(2009).

57. S. M. Habibi-Khorassani, A. Ebrahimi, M. Maghsoodlou, O. Asheri, M. Shahraki, N. Akbarzadeh, Y. Ghalandarzehi, Int J Chem Kinet. 45, 596 (2013).

58. S. M. Habibi-Khorasani, M. T. Maghsoodlou, A. Ebrahimi, F. Farahani-Vasheghani, E. Mosaddeg, M.A. Kazemain, Tetrahedron Letters. 50, 3621 (2009).

59. S. M. Habibi-Khorassani, A. Ebrahimi, M. T. Maghsoodlou, M. Zakarianezhad, H. Ghasempour, Z, Ghahghayi, Curr. Org. Chem. 15, 942 (2011).

60. M. Dehdab. S. M. Habibi-Khorassani, M. Shahraki, Catal. Lett, 144, 1790 (2014).

61. L. m. Schwartz. R. I. Gelb. Anal. Chem. 50, 1592 (1978).

62. G. Lente, I. Fabian, A. J. Poe New J. Chem. 29 759 (2005).

63. J. H. Espenson, McGraw-Hill, New York, 2, 158 (1995).

64. A. J. Poe, M. V. Twigg, Plenum Prss, New York. 10, 220. (1994). 